\title{
Las organizaciones comunitarias como instituciones intermedias: las Juntas de Acción Comunal en el municipio de Tenjo
}

Community organizations as intermediary institutions:

The boards of Community action in the municipality of Tenjo

\author{
Martha Milena Bautista Gómez \\ Máster en Problemas Sociales - Universidad de Granada \\ milebg@gmail.com
}

Artículo de investigación

Fecha de recepción: 3 de febrero de 2011 • Fecha de aceptación: 8 de abril de 2011

\section{RESUMEN}

Este artículo surge como producto de los resultados de la investigación realizada como trabajo de grado para la obtención del título de socióloga, llamada "Las organizaciones comunitarias como instituciones intermedias, aplicado a las Juntas de Acción Comunal (JAC) en el municipio de Tenjo", la cual tiene como propósito explicar el cambio en la funcionalidad de las JAC, como instituciones intermedias, en términos de su estructura organizativa y su relación con el Estado y la comunidad.

Palabras clave: organizaciones comunitarias, instituciones intermedias, Juntas de Acción Comunal.

\section{Abstract}

This article is based on research: "The community organizations and intermediary institutions, applied to the Community Action Committees (JAC) in the municipality of Tenjo" that was conducted for degree as Sociologist. The focus of the article is to explain the change in the functionality of the JAC as intermediary institutions, in terms of its organizational structure and its relationship with the state and the community.

Keywords: Community Organizations, Intermediary Institutions, Community Action Committees. 


\section{INTRODUCCIÓN}

En el escenario político, hoy cobra especial importancia la emergencia de nuevos actores que interactúan en el marco de una democracia participativa adoptada por el Estado como forma de gobierno, la cual se fundamenta en una actuante sociedad civil, que en el ejercicio de su ciudadanía es capaz de incidir en las decisiones públicas. Dicha incidencia se basa en el establecimiento de instituciones intermedias que se constituyen como cuerpos representativos de la comunidad frente al Estado, al cual controlan y limitan.

El estudio de estas instituciones intermedias principalmente ha estado dirigido hacia el análisis de los partidos políticos como sistema convencional de representación. Sin embargo, hoy han incursionado identidades colectivas diferentes, a través de organizaciones comunitarias de base que profundizan la democracia participativa mediante la autogestión y organización de la comunidad en la solución de las demandas sociales.

Son estas organizaciones de base, en su función de intermediación entre el Estado y la comunidad, el objeto de estudio de esta investigación. Concretamente se analizarán las Juntas de Acción Comunal (JAC) en el municipio de Tenjo, las cuales han tenido un proceso histórico de gran importancia y muy significativo a nivel nacional, llevando a cabo procesos reales de democracia participativa en una relación de convergencia entre Estado y sociedad civil. Hoy, sin embargo, son organizaciones fragmentadas en su tejido organizativo interno, como también en las relaciones que establecen con la comunidad y el Estado.

\section{REFERENTES METODOLÓGICOS}

Teniendo como objetivo principal explicar el cambio en la funcionalidad de las JAC como instituciones intermedias en el municipio de Tenjo, en cuanto a su estructura organizativa, así como en su relación con el Estado y la comunidad, se empleó como estrategia metodológica la etnografía. Se buscó comprender los fenómenos sociales desde el punto de vista de sus actores, haciendo una descripción que responda al qué, para qué y cómo es la realidad para ellos, con el fin de articular estas experiencias con las estructuras conceptuales, que en este caso están dadas desde la sociología política. 
Bajo esta estrategia etnográfica, se estableció como población objeto de la investigación a las Juntas de Acción Comunal (JAC) en su condición de instituciones intermedias, por lo cual los informantes fueron en primera instancia los líderes comunales y posteriormente, funcionarios de la alcaldía municipal y habitantes de Tenjo, con respecto al tejido social que construyen en torno a las JAC.

Se trabajó casi en su totalidad con fuentes primarias, ya que el material disponible en fuentes secundarias es muy escaso, en tanto no está documentado el proceso histórico de las JAC. Los datos que se encuentran provienen de la memoria colectiva del municipio, razón por la cual se emplearon como técnicas la observación participante, la entrevista abierta y semiestructurada, las historias orales y los grupos de discusión, hasta llegar a lo que se consideró un punto de saturación de la información requerida.

En cada una de las técnicas empleadas se buscó comprender la realidad sociocultural desde el discurso espontáneo de los actores, en cuanto a su conocimiento vivencial sobre un hecho que los lleva a expresar opiniones, puntos de vista o emociones significativas. Se contrastaron distintas reflexividades frente al proceso de institucionalización de las JAC, los elementos de ruptura y proceso de desinstitucionalización y sus condiciones actuales.

Se examinó en cada uno de estos momentos la relación articulada o desarticulada entre el Estado y la comunidad, mediadas por las JAC, analizando los elementos de cambio de representatividad para la comunidad, el fomento dado por las políticas públicas desde la alcaldía municipal para fortalecer las organizaciones de las sociedad civil, y la organización interna de las JAC.

\section{REFERENTES TEÓRICOS}

\section{Ciudadanía y sociedad civil}

La ciudadanía surge cuando el individuo toma una posición frente a su realidad, una ubicación frente a los otros; cuando se convierte en un ser capaz de decidir y de decidirse (Castoriadis, 2002, p. 8). De esta forma, el individuo entra en el campo social histórico desempeñando un papel de ciudadano y es entonces cuando influye en la sociedad, interviniendo como sujeto dotado de derechos y deberes, que conoce 
las disposiciones de los mismos, y es autónomo en el ejercicio efectivo de sus posibilidades como ciudadano, participando en la toma de decisiones dentro del poder público.

De esta forma, los ciudadanos empiezan a exigir demandas frente al Estado que no pueden ser satisfechas de forma individual, de manera que necesitan organizarse colectivamente con otros individuos, que se convierten en medios para el fin del individuo particular. Se pasa así de una sociedad compuesta por individuos a una sociedad civil compuesta por ciudadanos.

La sociedad civil es la afirmación de derechos naturales que pertenecen al individuo y a los grupos sociales, y que como tales limitan y restringen la esfera del poder político. De esta forma, la sociedad civil se constituye como subestructura, y es la que da el poder legítimo al Estado, el cual, a su vez, como superestructura funciona con el poder que le otorga la sociedad, para tomar decisiones sobre ella (Bobbio, 2001, p. 47).

En este sentido, la sociedad civil permanentemente deslegitima y relegitima al Estado. Su gestión es fundamental para la construcción de una gobernabilidad democrática, al desarrollar mecanismos y prácticas que le permiten intervenir en la definición, ejecución y monitoreo de las políticas públicas, creando espacios que favorecen el debate colectivo y formas de contrapoder civil respecto del poder del Estado. Es así como la sociedad y el Estado se constituyen como dos momentos necesarios, separados pero contiguos, diferentes pero interdependientes, del sistema social en su complejidad y en toda su articulación (Bobbio, 2001, p. 67).

\section{Instituciones intermedias}

Los grupos intermedios, que articulan la relación entre el Estado y la sociedad, tradicionalmente han sido constituidos por los partidos políticos, como un conjunto de miembros que se asocian para promover el bien común, conformando la voluntad colectiva que se organiza para dictaminar la política nacional:

Estos partidos son la estructura central intermedia e intermediaria entre la sociedad y el gobierno; constituyen un sistema de interacciones, en donde se convierten en una estructura de compensaciones y oportunidades, legitimadas 
por la voz del pueblo, formándose con base en un interés común (Sartori, 1980, p. 89).

La función primordial de los partidos políticos como organizaciones intermedias es constituirse como cuerpos representativos de la sociedad frente al Estado, canales intermediarios entre gobernantes y gobernados, siendo representativos de las comunidades que se expresan a través de ellos. Por tanto, quienes ejercen el papel de representantes, tienen que sentir la expectativa de aquellos a quienes representan, como una expectativa vinculante.

Sin embargo, esta democracia formal y su sistema convencional de representación a través de los partidos políticos, envejecen al no conseguir absorber y canalizar las demandas sociales y las necesidades de justicia. Esto permite que se creen condiciones de participación para identidades colectivas diferentes, a través de organizaciones comunitarias que adquieren un pleno significado si el espacio público comunitario alcanza, en diferentes niveles, formas de democracia participativa de base.

Estas organizaciones comunitarias, orientan y guían a la comunidad, trabajando de manera directa y constante con grupos poblacionales a los cuales tratan de nuclear y movilizar en torno a la construcción de bienes públicos, contribuyendo de esta forma al mejoramiento de la calidad de vida de sus comunidades.

Se convierten, por tanto, en interlocutores legítimos de sus comunidades frente al Estado. Aunque ejercen las mismas funciones de representatividad e intermediación que los partidos políticos, a diferencia de estos, sus intereses van más ligados a los grupos de base, siendo estos más restringidos y estableciendo un vínculo directo con la comunidad, al ser ellas las instancias más cercanas a las necesidades y aspiraciones de los individuos y más fácilmente controlables por ellos mismos.

\section{Estructura interna de las organizaciones intermedias}

Estas organizaciones construyen un tejido social que no solo se reproduce al interior de su estructura organizativa, sino que además se extiende hacia el entorno a través de las relaciones y vínculos que establecen con sus pares y otros actores. El tejido social que construye una organización implica tres tipos de vínculos: al interior de las 
comunidades de conocidos, en conexión horizontal con otras organizaciones en otras partes, y finalmente con las estructuras de mayor poder donde radican en última instancia las decisiones externas que afectan a la comunidad (Torres, 2003, p. 36).

Cuando estas organizaciones intermedias entre la sociedad y el Estado son sólidas a nivel interno, en cuanto a las directrices que guían su acción, así como su forma de leer las necesidades y su visión para abordar las soluciones; y cuando a su vez logran consolidarse como cuerpos representativos de la comunidad, articulando los distintos actores de una población y respondiendo a sus distintos intereses, empleando los espacios y canales de participación desde el Estado, constituyéndose como contrapoder civil, estas organizaciones se institucionalizan en la comunidad.

En este proceso de institucionalización, las organizaciones intermedias crean unas redes de significaciones que orientan la vida social; significaciones e imaginarios sociales que son instituidos y compartidos por una colectividad, dan sentido al mundo histórico-social, construyendo una verdad socialmente instituida, de acuerdo con los cánones de las representaciones, que constituyen procedimientos de validación, creando un orden y estableciendo unas normas, valores, lenguajes e instrumentos (Castoriadis, 2002, p. 68).

En conclusión, la función de estas instituciones intermedias es ser legítimas para la sociedad a la que representan, en cuanto a la solución autogestionada de las demandas sociales, constituyéndose como canales de expresión frente al Estado. Restringen el poder arbitrario de este último, convirtiéndose en actores políticos incidentes, conocedores de sus derechos, y de los mecanismos públicos existentes mediante un proceso de participación real. Lo anterior se da en el marco de una democracia sustancial, en donde la sociedad organizada haga uso de su soberanía, direccionando las políticas públicas que guían el desarrollo social, económico y cultural, para que este realmente sea un proceso integral que permita el mejoramiento de la calidad de vida. 


\section{RESUlTADOS DEL PROCESO DE INVESTIGACIÓN}

\section{El movimiento comunal de los ańos ochenta y noventa}

\section{Procesos de democracia participativa a través de las Juntas de Acción Comunal}

En el municipio de Tenjo, los primeros trabajos comunitarios se enmarcaron bajo unos fuertes lazos de solidaridad, hacia los años cincuenta y sesenta, periodo en el que la población era de menor extensión, y de escasos vínculos con otros municipios. La vida social de Tenjo en ese entonces conservaba los lazos comunitarios como forma de organización. Principios como la vecindad y relaciones de compadrazgo mantenían a la población en una permanente solidaridad, donde predominaban los vínculos primarios entre las personas, impulsadas por una voluntad natural, encaminadas a satisfacer sus intereses comunes.

La población tendía a ser estática, sus relaciones internas se sustentaban en la base de la familia, y las externas eran conducidas por los preceptos de la Iglesia y la escuela como centro de la vereda. Es a través de estas dos instituciones que la vida del campesino se empieza a organizar, creándose la primera cooperativa de ahorro y crédito en el municipio, Cooptenjo, en 1971, así como el grupo Coprolco. En 1974, se logra obtener por parte del Ministerio de Agricultura el financiamiento para la adquisición de un tractor que beneficia a los pequeños productores con la posibilidad de trabajar la tierra a un costo por debajo del establecido por el mercado. Con las utilidades del alquiler del tractor se empieza a pagar la deuda y a conseguir recursos para crear una tienda comunal que les diera el modo de subsistir y generar recursos para servir a la comunidad (Yazo y Nemocón ${ }^{1}$, comunicación personal, 22 de agosto de 2006).

Bajo este escenario surgen las JAC en los años sesenta, las cuales fueron concebidas por el Estado como organizaciones sociales dedicadas a trabajar por el bienestar de las comunidades locales, a través de proyectos de infraestructura, equipamientos y servicios sociales. La creación de estas juntas a nivel nacional, tenía como fin que las comunidades organizadas a través de las JAC colaboraran con el Estado en el mejoramiento de sus condiciones de vida.

1 Líderes tradicionales del municipio. 
En Tenjo, las JAC surgen en torno a la solución de problemas compartidos referentes a la falta de servicios públicos y arreglos de infraestructura básica, como problemas iniciales que aborda la organización, que se convierten en el pretexto y guía de la acción colectiva, creando a su vez espacios de formación y acercamiento a la comunidad, asumiendo en un momento dado responsabilidades que le competían al Estado, pero que realizaban las JAC.

En los ańos setenta las JAC se organizan a nivel municipal en Asojuntas, como una organización social sin ánimo de lucro, con personería jurídica, conformada con la participación de los presidentes de las juntas de las 16 veredas del municipio.

Simultáneamente, en la década de los ochenta tiene gran influencia la emergencia del Nuevo Liberalismo que se daba a nivel nacional, y que en Tenjo tuvo gran acogida; en primera instancia, porque es un municipio de tradición netamente liberal, y también porque fue adoptado ideológicamente por el movimiento comunal, que en este entonces era muy fuerte.

Un hito de gran impacto que fortalece el movimiento comunal es la aprobación de la reforma municipal en 1986 sobre la descentralización y la elección popular de alcaldes, además de la institucionalización de un conjunto de canales de participación a través de los cuales los ciudadanos pueden incidir en las decisiones locales.

A partir de este momento, la acción comunal en Tenjo empieza a tener acceso al poder político, inicialmente en el Concejo Municipal, donde este empieza a ser una fuerza decisoria, empezando a generar procesos reales de participación comunitaria, haciendo control político, social e informando a la comunidad sobre la gestión del Concejo a través de cabildos abiertos, de comunicados, o acudiendo directamente a las veredas (C. Castro ${ }^{2}$, comunicación personal, 10 de septiembre de 2006).

Asimismo, el movimiento comunal accede también a la alcaldía ganando las elecciones de 1986, que eran las primeras por voto popular, cuando llegó al poder el líder comunal Sofanor Salas. De esta manera, quedan cubiertas por el movimiento las dos instancias políticas más importantes, el Concejo Municipal y la Alcaldía,

2 Alcaldesa de Tenjo 1998-2000. 
que ya teniendo recursos propios por medio de las transferencias de presupuesto al municipio, empieza a dar un gran apoyo a la acción comunal.

Bajo este esquema participativo, se desarrollan importantes trabajos comunitarios como la construcción del acueducto municipal con el que se logra abastecer de agua potable a las veredas, servicio que únicamente era suministrado en el casco urbano. Esto permanece en la memoria colectiva como la mayor muestra de participación comunitaria, en la que convergen tanto el apoyo de la institucionalidad a través de la gestión y el capital de la alcaldía, como la organización de la comunidad a través de las JAC, cuyos líderes ejercen un papel no solo como mediadores sino además como activos protagonistas del proceso. Tienen así la capacidad de interpretar y representar los intereses colectivos y de transmitir valores y actitudes a los miembros del grupo, con lo cual logran cohesionar y organizar a la comunidad, como orientadores de la acción colectiva, debido a la credibilidad y confianza que representan.

Posteriormente, queda por segunda vez un líder comunal en la alcaldía, se afianza esta relación, y se da un marcado enfoque participativo desde las políticas públicas. La primera muestra de esto se dio en el plan de desarrollo, que se realizó de forma participativa con 3.500 personas, por lo cual se gana el primer premio a nivel nacional por la participación de la comunidad en su elaboración. De esta forma se empezó a construir un diagnóstico rural desde la comunidad vereda por vereda, y se priorizaron las soluciones que había dado la comunidad, de lo cual se desprendieron proyectos y programas que hicieron posible la administración (C. Castro ${ }^{3}$, comunicación personal, 10 de septiembre de 2006).

También en este periodo Asojuntas crea la tienda comunal, que fortalece altamente al movimiento comunal, como uno de los ejemplos más representativos y de mayor reconocimiento. La tienda se creó con el fin de poder estabilizar y regular los precios de la canasta familiar, así como un mecanismo por medio del cual las JAC de cada vereda pudieran tener fondos para sus necesidades y las de la comunidad. La dinámica de la tienda fue un éxito de las JAC y de la asociación, llegando a tener más de 40 empleados y tres sedes, con lo cual se cumplía una función social importante dentro

3 Alcaldesa de Tenjo en el periodo 2005-2008. 
del municipio, como generadora de empleo para los mismos tenjanos y reguladora de los precios altos que manejaban otros comerciantes.

Son muchos los logros alcanzados por las JAC como ejemplo de sociedad civil y de procesos democráticos desarrollados. La construcción del acueducto y la tienda comunal son los más representativos pero no los únicos; fueron muchas las obras de mejoramiento de infraestructura en los caminos veredales, en los servicios públicos, en la construcción de escuelas e incluso del hospital municipal, todas ellas como producto de una gran gestión de las JAC en cogestión con los recursos de la alcaldía y el trabajo de la comunidad.

\section{Pérdida de autonomía y fragmentación de las JAC}

El movimiento comunal continúa su vinculación con lo político, y esto empieza a generar problemas en cuanto a los primeros indicios de pérdida de autonomía del movimiento y divisiones internas. Es así como se propone como candidato a la alcaldía a Luis Fernando Restrepo, presidente de Asojuntas, y gestor de la tienda comunal, pero a raíz de una división al interior del movimiento, también se postula Hansy Zapata. Como consecuencia de la división de votos entre dichos candidatos, resultó elegida en 1991 Clementina González, representante del oficialismo liberal y los floricultores, por lo cual la relación del movimiento comunal con la alcaldía fue de enfrentamiento directo y oposición radical ${ }^{4}$.

En este caso, como en la mayoría de los movimientos sociales latinoamericanos, empieza a ser difusa la separación entre Estado y sociedad civil y termina siendo privilegiada la acción estatal, subordinando a los actores sociales al poder político, lo cual hace que el movimiento se debilite a causa de la división de sus miembros, como consecuencia de la inclusión de direcciones políticas al movimiento (Touraine, 1989, p. 233)

Además de lo anterior, en este periodo el movimiento comunal es fuertemente golpeado, al entrar en vigencia la nueva Constitución de 1991, en la que se prohíbe tácitamente la entrega de donaciones a particulares, por lo cual las juntas dejan de

4 Entrevistas a líderes realizadas durante la investigación en el periodo comprendido entre enero y diciembre del año 2006. 
recibir el auxilio económico de la alcaldía y además el ingreso que recibían por concepto del acueducto.

De esta manera, las juntas asumieron los efectos negativos de la implantación de la nueva Constitución, pero no adoptaron los mecanismos e instrumentos de participación que esta plantea, pues aunque se eliminaron los auxilios económicos, una de las motivaciones más importantes del cambio constitucional era fomentar la participación comunitaria y fortalecer la sociedad civil, es decir, una institucionalidad política basada en la participación ciudadana trascendiendo la democracia representativa y procurando una intervención directa de la ciudadanía. Sin embargo, todos estos mecanismos de una $\mathrm{u}$ otra forma han sido subutilizados por la acción comunal, en muchos casos por desinformación, pero también porque a partir de esto la asignación de recursos hacia las JAC depende mucho de la orientación política del alcalde del momento, lo cual cada vez se hizo más evidente, así como mayor la pérdida de autonomía del movimiento comunal.

Adicionalmente al impacto de los cambios políticos, las JAC son altamente afectadas cuando la tienda comunal entra en crisis, y después de llegar a tener un capital de 3.114 millones de pesos se pasaron a deber 450 millones de pesos (L.F. Restrepo ${ }^{5}$, comunicación personal, 5 de mayo de 2006). Son muchas las historias que existen en torno a la liquidación de la tienda comunal, pero en términos generales se evidencia que faltó un control de vigilancia adecuado y de direccionamiento por parte del comité administrativo. No se tenía el suficiente conocimiento sobre la organización empresarial, de forma que la tienda comunal creció tanto económicamente, que no se supo controlar y se salió de su cauce.

Aunque las JAC eran mucho más que la tienda comunal, su desaparición permanece en el imaginario social como un fracaso de descrédito de las JAC y sus líderes, y como un estancamiento de la función social de Asojuntas, que a partir de este momento desvía su horizonte comunitario y se dedica inicialmente a salvar la tienda y luego a arreglar los problemas jurídicos derivados de su liquidación.

5 Gestor de la tienda comunal. 
De esta forma, las JAC evidencian ampliamente problemas de fragmentación de su tejido social como asociación, mostrando divisiones al interior del grupo por corrientes políticas, distanciándose cada vez más tanto de la alcaldía, la cual pierde credibilidad para las juntas, como de la comunidad, que al ser cada vez más compleja, no logra ser organizada por las juntas comunales.

\section{Juntas de Acción Comunal como organización comunitaria}

En Tenjo existe una JAC por cada una de las 16 veredas, con personería jurídica, y constituida por un presidente, vicepresidente, fiscal, tesorero, secretario y vocales y varios comités de apoyo, las cuales a su vez se encuentran organizadas en Asojuntas. Como se explicará, actualmente las JAC en su organización interna enfrentan una gran fragmentación en su tejido asociativo, producto tanto de factores externos como se mencionó en el proceso de desarticulación, como a nivel interno entre sus líderes.

\section{Crisis del discurso comunal}

En primera instancia, en Asojuntas no se evidencia unidad en la direccionalidad de las juntas y los objetivos a alcanzar. Aunque cada presidente realiza actividades importantes en sus juntas para solucionar las necesidades de su comunidad, en conjunto estas no están encaminadas hacia un fin común. Y teniendo en cuenta que es a través de los líderes que las JAC ejercen la función de representación para la comunidad, es importante la articulación entre ellos, pues son quienes direccionan la conducta de la comunidad, y su legitimidad se la concede la confianza en sus aptitudes personales, lo cual es quebrantado por una división interna que les resta credibilidad frente a su comunidad y eficiencia en su labor.

En cuanto a las formación de los líderes, aunque existen algunas capacitaciones en el municipio, estas son pocas y el nivel de confrontar experiencias y de formación política se ha perdido casi en su totalidad. Las deficiencias tanto en conocimientos sobre los parámetros existentes para ejercer sus derechos, como en formación política para direccionar la organización, son los elementos más relevantes generadores de ruptura como grupo internamente, así como en su relación con la comunidad. En este sentido, el discurso que los sustentaba como movimiento comunal en un momento dado, en el que se autodenominaban como representantes de las necesidades de una 
población campesina, con muchas necesidades por resolver en cuanto a infraestructura y dotación de servicios, bajo la corriente del nuevo liberalismo que proclamaba cambios radicales en la estructura estatal, es un discurso que ha perdido vigencia y nunca fue modificado.

Esta pérdida de vigencia del discurso de las JAC cuestiona altamente su legitimidad en la comunidad y se da como consecuencia de no plantearse a nivel interno procesos autorreflexivos como organización, en cuanto a la relectura de necesidades de acuerdo con los cambios sociales del municipio y formas viables de abordar la solución. Por tanto, son necesarios procesos de formación política y participativa, de reencausar la cultura política democrática y darle una direccionalidad a la organización.

En parte, esta crisis de liderazgo está dada por la falta de apertura como organización para la formación de una nueva generación de líderes, lo cual acabó por desarticular su relación con la comunidad. La integración de nuevos líderes permite que se reoriente la acción de una organización comunitaria y que la representación no se concentre en pocas manos, permitiendo la apertura de un espacio cada vez más democrático y participativo, vinculado a los intereses de las bases sociales.

\section{Tipología de líderes}

Actualmente, la figura más importante de cada junta son sus presidentes, que en su gran mayoría son tenjanos que han vivido toda su vida o la mayor parte de ella en la vereda a la que representan. Son muy pocos los casos en que los nuevos pobladores del municipio asumen la responsabilidad de la acción comunal. Dentro de ellos se pueden identificar tres tipos de líderes: los tradicionales campesinos; los que tienen un arraigo fuerte campesino pero han recibido el impacto de la urbanización social del campo; y los que tienden mucho más hacia el ritmo de vida urbano, algunos de los cuales trabajan en centros urbanos, y otros incluso vienen a Tenjo esporádicamente.

Sin embargo, la comunidad no recuerda resultados palpables de su labor actual, como ocurrió en otro tiempo en donde la instalación del acueducto, del alumbrado público y el mejoramiento de los caminos eran resultados tangibles para la comunidad, que además los involucraba y beneficiaba a todos. Ahora, en contraste, las actividades que realiza el líder están más dispersas y desarticuladas, en parte por la misma naturaleza de los problemas que ya no son tan claramente compartidos por la comunidad. 
Toda esta situación devela dos aspectos. Por una parte, la dificultad de la labor del líder, pues aunque tenga una vocación de servicio a la comunidad, es difícil cuando no recibe ningún tipo de apoyo, ya que la comunidad, al depositar su confianza en el líder, se desentiende por completo de las actividades y proyectos, por lo cual este debe disponer de mucho tiempo que no siempre tiene. El hecho de que los líderes no tengan un estímulo económico desmotiva, así como la poca importancia que le concede la comunidad a su labor ${ }^{6}$.

Al mismo tiempo, es cuestionable su capacidad de liderazgo, porque como se mencionó al principio, una de las condiciones fundamentales del líder es su carisma para mover voluntades y legitimar su dominación, al saber transmitir valores y actitudes a los miembros de su grupo para motivarlos, y a su vez tener la capacidad de apertura a nuevos líderes, condiciones que no se cumplen en la gran mayoría de líderes actuales.

Sin embargo, aunque las problemáticas son generales a todos los líderes, existen diferencias significativas entre ellos, pues aunque el problema de comunicación con la alcaldía y la falta de recursos es general, hay quienes tienen mayor capacidad de gestión de las necesidades de la población a la que representan. Lo mismo ocurre con el problema de la convocatoria a la comunidad, que igualmente es compartido por todos los miembros de las JAC; sin embargo, hay algunos cuya gestión es relativamente representativa, por lo que aún logran reconocimiento en su comunidad, y otros que "todavía viven de la historia de cuando recibían el auxilio económico y de cuando la tienda comunal tuvo su mayor apogeo, de forma que viven desencantados de una historia pasada, en donde las bases sociales ya no les creen" (M. Gallego ${ }^{7}$, comunicación personal, 5 de mayo de 2006).

\section{Redes con otras organizaciones}

Una vez se consolida el tejido social a nivel interno en la organización, se dan procesos identitarios como grupos que luego se enriquecen al compartir experiencias con otras organizaciones de naturaleza similar, de la cual se aprenden experiencias. Esto

6 Entrevistas a los presidentes de las JAC, realizadas durante la investigación en el periodo comprendido entre febrero y marzo del año 2006.

7 Secretario de la junta directiva de Asojuntas. 
les permite diferenciarse como organización y a su vez establecer vínculos y redes de mayor envergadura (Torres, 2003, p. 137).

Dado que actualmente las JAC no logran ser representativas de los diferentes tipos de pobladores y sus nuevas necesidades, han surgido alternamente otro tipo de organizaciones comunitarias, que responden a sectores específicos de la población y que buscan solucionar necesidades no solo materiales, sino también de carácter simbólico. Es así como han emergido otras formas de organización social de la comunidad, tales como asociaciones, cooperativas, grupos productivos, grupos de veedurías ciudadanas, etc., las cuales conforman el tejido asociativo del municipio, y además son muestra de formas de participación en la construcción de una sociedad civil.

Sin embargo, actualmente son pocas las organizaciones comunitarias que subsisten en Tenjo. Por lo general son grupos de corta duración, muchos de los cuales surgen para solucionar una necesidad coyuntural, pero no se logran conformar como organización. En general, la gran mayoría de las organizaciones actuales parten de una iniciativa estatal, que luego se enriquece y se pone en marcha con la comunidad; no obstante, la comunidad presenta problemas para organizarse y tener permanencia, enfrentan dificultades tanto en su organización interna como en su relación con la comunidad y el Estado.

Dentro de estas organizaciones actuales, como muestra de la incidencia de la sociedad civil organizada hoy en Tenjo, se pueden diferenciar dos tipos de organizaciones. Las primeras buscan solucionar una necesidad eminentemente económica de un grupo social específico como cooperativas y grupos productivos, las cuales no tienen ningún tipo de articulación con las JAC, puesto que responden a intereses diferentes. Sin embargo, podría haber una articulación en el sentido que desde las JAC se propiciaran espacios de agremiación para fomentar las empresas de economía social e impulsar y ejecutar programas que promuevan el desarrollo integral.

El otro tipo de organizaciones que existen en Tenjo, van dirigidas al beneficio de la comunidad en general, y tienen una finalidad social de diversa índole que incursiona en temáticas ambientales, de protección a la infancia y veedurías ciudadanas. Pese a que deberían tener una fuerte articulación con las JAC, estas organizaciones, por una parte, han surgido prácticamente como opositoras a las juntas por considerarlas in- 
eficientes en su labor y ligadas al clientelismo político, y por otra parte, se enfocan en nuevas necesidades de la población que en pocos casos están insertas en las JAC. La articulación de estas organizaciones de sentido social podría ser más de complementariedad que de oposición, ya que es transversal a ellas el desarrollo de procesos de empoderamiento y autogestión a fin de convertirse en nuevos actores políticos, como interlocutores legítimos entre la sociedad y el Estado. Sin embargo, en la actualidad se dan como procesos dispersos.

En conjunto, se han resumido los grupos sociales que representan y aglutinan esfuerzos y reclamos plurales de participación y transformación en la vida social del municipio. Ninguno de ellos se ha institucionalizado frente a la comunidad como contrapoder frente al Estado. No dejan de ser esfuerzos dispersos que no se canalizan hacia un fin último de injerencia de la ciudadanía en la vida pública; por tanto, las JAC, aún en su fragmentación actual, continúan siendo los interlocutores más legítimos de la comunidad frente al Estado, pese a que han dejado de ser representativas de los diferentes tipos de pobladores.

\section{Relación de las JAC con la comunidad y el Estado}

Gran parte de la institucionalidad de las JAC y de los importantes logros que tuvieron se dio en términos de una relación de convergencia y alianza en sus relaciones con el Estado como actor incidente en las decisiones públicas, y con la comunidad en su función de representatividad e institucionalidad. Estas relaciones, a la par con la fragmentación interna de las JAC como organización, experimentaron importantes rupturas, como se verá a continuación, que conducirían a un proceso de desinstitucionalización.

\section{Las JAC y sus relaciones con la comunidad}

El municipio experimentó dos cambios sociales importantes, marcados por un fenómeno migratorio de gran impacto. Mucha población llegó al municipio al amparo de la oferta laboral de las agroindustrias de flores. A su vez, se produjo un proceso de urbanización social del campo como consecuencia de un cambio en su vocación económica, de la cercanía y dependencia con la ciudad de Bogotá, y en general por los acelerados cambios que experimentó la sociedad colombiana en detrimento de los sectores rurales. 
Estos cambios hacen que las relaciones sociales se transformen, pues están determinadas por la división del trabajo, el contacto sociocultural, el cambio de mentalidad y expectativas de la población, así como una movilidad social por canales no previstos, transformaciones en tecnología, formas de propiedad y emergencia de nuevas clases y estratos que enriquecen el tejido social rural. Asimismo, se dan cambios en el paisaje cultural, la dinámica demográfica, los tipos de poblamiento, el uso del suelo y las relaciones de producción.

En este proceso, el campesino tiene un contacto progresivo con diferentes grupos sociales, rurales y urbanos, instituciones, intermediarios y agencias de crédito, entre otros, que amplían su horizonte y producen grandes cambios en sus instituciones societarias, traspasando sus relaciones básicas de la familia, la vereda y el poblado (Jaramillo, 1988, p. 89).

Por consiguiente, al reducirse las relaciones cara a cara, basadas en vínculos primarios y comunitarios, los individuos ganan un mayor margen de autonomía, lo que les permite actuar más libremente con el otro. Lo que prima en una sociedad con gran cantidad de población heterogénea, como la población tenjana, son contactos a través de intercambios, por los que se actúa conjuntamente sin que surja una voluntad comunal. Si dicha voluntad se da es de forma esporádica o como residuo de estados anteriores que le sirven aún de fundamento.

Todo lo anterior produjo en Tenjo un proceso de conurbación, de permanente intersección entre lo rural y lo urbano que no pueden comprenderse en términos de simple oposición, sino de complejidad y complementariedad (Misión Bogotá, 1991, p. 37). Aunque ha habido grandes modificaciones en el modo de vida del campesino tenjano con la incursión de la urbe, el pasado y la tradición no se han perdido; lo que ha ocurrido es que se han resignificado y adaptado a una realidad híbrida. Hoy no se puede hablar de una auténtica cultura campesina en Tenjo, ni tampoco de auténticos citadinos. El escenario y el contacto con una naturaleza poco modificada, así como las relaciones comunitarias establecidas, el arraigo a la tierra y el vínculo con actividades agrícolas, marcan diferencias entre la vida de Tenjo y de la ciudad.

Como consecuencia de estos cambios, hoy la población tenjana es muy heterogénea; en términos generales, se pueden identificar como tipos de pobladores-campesinos, 
desplazados, población obrera, cuidanderos de fincas, industriales y finqueros-, lo cual ha hecho que los lazos de solidaridad, que en un momento dado fomentaron los procesos participativos, en cuanto a organizarse como comunidad y dar solución a sus necesidades en torno a las JAC, hoy se hayan visto fragmentados. Al hacerse una población heterogénea, sus necesidades son diferentes y esto hace que se complejice la participación en las organizaciones comunitarias, más aún cuando las JAC, como organizaciones comunitarias, siempre han respondido a intereses y necesidades homogéneos de una población netamente campesina.

Por tanto, para muchas personas, las JAC hoy no cumplen su función como representantes, y sin embargo, se sigue insistiendo en ellas por el desarrollo histórico significativo que tuvieron, como lo dice uno de sus habitantes:

...yo considero que la acción comunal, en una época fue el movimiento perfecto, pero todo como es en la vida, nos pasa a los humanos, pasamos el ciclo. El ciclo de la acción comunal pasó, pero aún siguen caminando en lo mismo, y siguen reviviendo un muerto (C. Forero ${ }^{8}$, comunicación personal, 21 de agosto de 2006).

Si bien es cierto que como organización las JAC presentan debilidades y falencias, también es importante tener en cuenta que esta heterogeneidad de la población hace que las necesidades ya no sean tan claras y por ende no haya una motivación compartida como elemento de movilización, como sus mismos habitantes los expresan:

...era muy buena la participación, cuando está la necesidad, a la gente le toca caminar en función de eso. Ahorita cuando ya no hay necesidades sentidas, no se mueven. Solo lo hacen por intereses que toquen sus vidas (R. Navarrete? Comunicación personal, 17 de septiembre de 2006).

Este factor, aunado a la tradición paternalista arraigada en la comunidad, hace que la población espere que todos sus problemas los solucione la administración pública, asumiendo una función únicamente receptora. La participación en las juntas de sus

8 Habitante de la vereda La Punta.

9 Ex presidente de la JAC de la vereda Chitasuga. 
veredas es muy baja. La gente no entiende que la junta es de la comunidad, para su beneficio, de manera que siempre estas están compuestas de las mismas personas que toman las decisiones. Por todo lo anterior, se puede concluir que hay una desarticulación de las JAC con la comunidad y por tanto, no son entes representativos de ella, ya que no articulan los diferentes tipos de pobladores de Tenjo, ni responden a las nuevas necesidades; no logran cumplir su función de organizadoras de la comunidad, y han perdido credibilidad por su relación con políticas clientelistas.

Bajo estas condiciones actuales de la población tenjana, las JAC deben transformar dicha complejidad en una oportunidad de ejercer control político sobre sus derechos como actores participantes de desarrollo en el municipio. Para lo cual deben adquirir una estructura organizativa con criterio gerencial, trabajando en proyectos que den mayor efectividad a su labor, teniendo como elemento base la comunicación con la comunidad, a través de diferentes mecanismos que fomenten el interés de la gente por la problemática de su municipio, de forma que estos se conviertan en sujetos activos que transformen su realidad a través de procesos de autogestión.

\section{Las JAC y el Estado}

Aunque en principio, antes de legalizarse jurídicamente, las JAC surgen como oposición al Estado cumpliendo las acciones comunitarias que este ignoraba, posteriormente se constituyen como un actor político fundamental, se inscriben bajo la corriente política del nuevo liberalismo y empiezan a generar importantes procesos de empoderamiento, que permitieron su incidencia real en las políticas públicas.

Esta incidencia de lo político, que en un primer momento le da un gran fortalecimiento y le permite acceder como movimiento comunal a instancias como el concejo municipal y la alcaldía, termina absorbiéndolo y debilitándolo, al quedar en entredicho su autonomía y empezar a generarse un conflicto político entre los comunales. Tal es en gran parte la razón de la fragmentación de su tejido social, pues produjo una división interna en las JAC entre partidarios y opositores de la alcaldía de turno ${ }^{10}$.

10 Entrevistas a los presidentes de las JAC, realizadas durante la investigación en el periodo comprendido entre febrero y marzo del 2006. 
Esta situación se da como consecuencia de un modelo de cultura política, que relaciona sistemáticamente tipos de orientaciones de acción política con tipos de estructura social y valores culturales, que estructuran instituciones y sedimentan significados a la acción social, expresada a través de la acción política. En Tenjo, siguiendo la misma línea del país, la cultura política se da a través de dependencias, cadenas de favores y contraprestaciones.

Es así como la forma de acceder al poder se da mediante la absorción de las elementales expresiones comunitarias que puedan existir, por considerarse un potencial electoral importante, de forma que se involucra a los líderes movilizadores de población, quienes se encargan de acercar el candidato a la comunidad en fiestas ofrecidas, en las que se llevan una serie de prebendas en medio de un discurso en el que se promete solucionar todos los problemas individuales ${ }^{11}$.

Este ha sido un factor de gran descrédito para las JAC, ya que siempre han tenido vínculos muy fuertes con el elemento político, por lo que se asume que como líderes buscan los beneficios personales, además de asociarse a los éxitos y fracasos políticos con los líderes participantes o simpatizantes de determinadas campañas políticas.

Por otra parte, en esta nueva relación con el Estado, se amplían los mecanismos y espacios de participación otorgados por la Constitución Nacional, la cual consigna la importancia del enfoque participativo en las políticas públicas desde su diseño hasta su implantación.

En este aspecto, aunque se han dado cambios importantes, la inclusión participativa a nivel legal no siempre implica su aplicación efectiva, pues tiene de trasfondo toda una tradición de cultura política a nivel nacional y en el caso local, en Tenjo, que dificulta el proceso. No se ha logrado romper totalmente con el paternalismo arraigado en las políticas públicas; la participación comunitaria en ella, aunque existe, es muy limitada. Hay una subutilización de los mecanismos por parte de las JAC y la comunidad en general, ya que no se educa desde la institucionalidad política para

11 Entrevistas a líderes tradicionales, realizadas durante la investigación en el periodo comprendido entre enero y diciembre del 2006. 
que sean ejercidos, luego la participación que se da en estos mecanismos es supremamente limitada.

La misma situación se presenta con instancias como el Concejo municipal y la personería, que siendo los entes más directos que deberían apoyar el proceso de las JAC, aunque existen, no cumplen esta función. Cabe anotar en este sentido que se presentan canales inadecuados de comunicación entre estos y las JAC, en una relación totalmente desarticulada y fragmentada, perdiendo la funcionalidad que en un momento tuvieron cuando a través de estas instancias de participación, las JAC como movimiento comunal intervenían como actores políticos.

Desde este punto de vista, se podría decir que realmente se potenciaría una democracia participativa, en la que el pueblo debe hacer uso de su soberanía, si existiera una voluntad política para democratizar el poder, y capacidad de participación efectiva de la población. Para ello, es fundamental un proceso de educación política, que en gran medida debe ser fomentado desde el Estado, permitiendo a la comunidad organizada acceder a nuevas valoraciones de los derechos y deberes ciudadanos para lograr un cambio de mentalidad en cuanto al papel de la sociedad y las instituciones en un sistema democrático.

En síntesis, no existe una relación funcional entre el Estado y las JAC, en la cual estas se fortalezcan al hacer uso de los mecanismos e instancias que les permitirían configurarse como contrapoder civil, puesto que por una parte las JAC son dependientes del Estado y por otra, hacen un uso muy limitado de los espacios que propicia la alcaldía. Por lo anterior, las JAC no ejercen un control político sobre la alcaldía, dado que no se ha logrado romper con el esquema paternalista, y por ende las JAC no ejercen su función de sociedad civil, ya que no se convierten en canales de expresión efectivos de la comunidad frente al Estado.

\section{Conclusiones}

Las JAC surgen en un momento en que la sociedad tenjana era una población rural, con gran cantidad de necesidades en cuanto a infraestructura y prestación de servicios por resolver, unida por fuertes lazos comunitarios, en los que la escuela y la iglesia se constituían como instituciones articuladoras de la comunidad. De esta forma, 
surge toda una generación de líderes comunitarios que logran motivar y articular a la comunidad en torno a la solución de un bien común, desarrollando una postura crítica frente a su realidad y capacidad de autogestión, determinada por el sentido de pertenencia hacia el municipio, teniendo en cuenta que la mayoría de la población era nacida en Tenjo.

En la actualidad, las JAC son en sí mismas redes, un entramado construido cotidianamente en la interacción con los habitantes de la comunidad, constituyéndose como canales de expresión, que le permitía a la población incidir en las decisiones de las políticas públicas a través de la representación de las JAC, como muestra de una sociedad civil generadora de procesos democráticos, mediante el uso de su soberanía popular, en el ejercicio de la ciudadanía.

A partir de allí, y junto con la realización de los trabajos comunitarios y con la representatividad a nivel político de las JAC, la legitimidad de su función permite que esta se institucionalice en la comunidad como un proceso de autonomía de la sociedad civil, que se despliega en una multiplicidad de formas organizadoras y organizadas. Como instituciones, las JAC eran dotadas de sentido por las significaciones imaginarias de la sociedad a la que representan, prevaleciendo por medio de la legitimidad y el consenso y creando individuos que las reproducen.

Sin embargo, el municipio empieza a experimentar una serie de acelerados cambios hacia los años noventa, producto de los procesos de urbanización y movimientos migratorios, los cuales afectan profundamente los lazos comunitarios, alterando sus formas organizativas y los términos en los que se constituyen como ciudadanía. De esta manera, se pasa de ser una comunidad relativamente homogénea a una altamente diferenciada, con diversidad de demandas sociales.

Paralelo a esto, se dan importantes cambios en los mecanismos de participación del Estado, que no fueron asimilados por las JAC, los cuales conservaron una relación viciada por el clientelismo y con un claro enfoque asistencial. En este sentido, las JAC dejaron de ser el contrapoder frente a la administración pública, que los constituía como el canal más efectivo para la solución de las demandas sociales. 
Frente a estos cambios, las JAC tenían que haber replanteado su función, ajustándose permanentemente a estas transformaciones. Al no hacerlo, no lograron responder a la heterogeneidad y las nuevas necesidades de la población y parámetros de relación con el Estado, por lo cual dejaron de ser representativas de ella, convirtiéndose en una organización ilegítima para la comunidad.

Sobreviene de esta forma, paulatinamente, un proceso de desinstitucionalización, como consecuencia de la crisis en el metarrelato de las JAC, en cuanto a un discurso que deja de ser representativo para la heterogeneidad de la población tenjana, y para el nuevo rol que debe asumir frente a la reestructuración del Estado. Lo anterior se debe a que no se dan procesos autorreflexivos como organización, en cuanto a la relectura de necesidades de lo material a lo simbólico, de acuerdo con los cambios sociales del municipio.

Es así como la comunidad vuelve a asumir un rol pasivo frente al quehacer del municipio, deja de ejercer su ciudadanía esperando recibir la solución a sus problemas de parte del Estado, por lo que es dependiente de él, e incapaz de limitar su poder. Es decir, que si bien es cierto que las JAC dejan de ser legítimas para la comunidad, a su vez esta deja de constituirse como sociedad civil, al no haber ciudadanos que exijan sus derechos y se conviertan en actores políticos. En su lugar existen individuos dispersos, que no permiten la existencia de instituciones intermedias, las cuales solo existen en la medida en que haya una sociedad civil sólida.

Esto se da como consecuencia de una ausencia de formación política y participativa de los líderes de las JAC que les permita reencausar la cultura política democrática. Por esta razón, nunca se modificó el discurso que los sustentaba como movimiento comunal, ni tuvieron la apertura para la formación de una nueva generación de líderes.

Frente a dicha crisis de representatividad y legitimidad de las JAC, se da una emergencia de diferentes organizaciones comunitarias en Tenjo, que develan la necesidad de la existencia de instituciones intermedias que articulen la relación del Estado y la comunidad; no obstante, ninguna de ellas se ha logrado institucionalizar estableciendo redes de significados que ordenan la vida social, como en un momento lo hicieron las JAC. Como instituciones intermedias nunca han sido reemplazadas, y pese a su 
fragmentación actual, continúan siendo los interlocutores más válidos para la comunidad, aunque no cumplan a cabalidad con su función.

En términos generales, es importante trabajar en la formación de nuevos líderes con el apoyo de la administración municipal. Hacen falta políticas de juventudes, que permitan un posicionamiento crítico de los jóvenes en cuanto a su quehacer en el municipio, ya que en gran parte fue la falta de renovación de líderes lo que deslegitimó su discurso al no ser capaces de ir adecuando su función con base en los cambios experimentados en su sociedad.

Necesariamente se tiene que sensibilizar a la comunidad, pues son ellos quienes deben liderar los procesos de participación comunitaria. Es fundamental trabajar en esta formación política de la comunidad como un proyecto a largo plazo, que se inicie desde la escolaridad, a fin de que la población desarrolle procesos de autogestión y empoderamiento.

El desarraigo que se evidencia hoy en día, y la renuencia de la comunidad a involucrarse en organizaciones comunitarias, no significa que como sociedad no necesiten de las instituciones intermedias. Esto obedece a una falta de educación política, por lo cual no son conscientes de la importancia de organizarse para la construcción de una democracia participativa que se fundamenta en el reconocimiento del poder que se tiene como sociedad civil para incidir en las políticas públicas, constituyéndose como contrapoder, exigiendo la solución de sus demandas mediante el ejercicio de su ciudadanía, por medio de la participación política, que solo se ejerce a través de cuerpos intermedios que se constituyen como instituciones sociales, mediante la articulación de la comunidad a través de la representación de las organizaciones intermedias.

\section{REFERENCIAS}

Amirita, R. M. (2002). Participación comunitaria en el ordenamiento territorial: caso aplicado al Municipio de Tenjo. Bogotá: Universidad Pedagógica Nacional.

Berger, P. y Luckman, T. (1970). La construcción social de la realidad. Buenos Aires: Paidós. 
Bobbio, N. (2001). Estado, poder y gobierno. México: Fondo de Cultura Económica.

Castoriadis, C. (2002). Ciudadanos sin brújula. México: Coyoacán.

Ceballos, M. (2001). Participación y fortalecimiento institucional a nivel local en Colombia. Bogotá: Pontificia Universidad Javeriana.

Flórez, M. (mayo de 2005). Construcción de capital social y organizaciones comunitarias en Bogotá Recuperado el 20 de agosto de 2006 de www.fundacioncorona. org.co/descargas/PDF_publicaciones/Gestion/Gestion_Capital_Social_Bogota. pdf

Jaramillo, J. (1988). Estado, sociedad y campesinos. Bogotá: Tercer Mundo Editores.

Ministerio del Interior. (1997). Digidec: Proyecto capacitación y asistencia técnica para la participación comunitaria. Bogotá: Coorpes.

Misión Bogotá. (1991). El futuro de la capital: un estudio prospectivo de las relaciones de Santafé de Bogotá con Cundinamarca. Bogotá: Siglo XXI.

Sartori, G. (1980). Partidos y sistemas de partidos. Madrid: Alianza Editorial.

Sartori, G. (1985). Fundamentos de sociología politica. Madrid: Alianza Editorial.

Torres, A. (2001). La organización comunal en Colombia. Bogotá: Banco de la República.

Torres, A. (2003). Organizaciones populares, identidades colectivas y ciudadania en Bogotá. Bogotá: Universidad Pedagógica Nacional.

Touraine, A. (1989). La palabra y la sangre: sociedad y política. Madrid: Espasa-Calpe.

Weber, M. (1964). Economía y sociedad (vol. II). México: Fondo de Cultura Económica. 